\title{
La generación del cambio climático global
}

\section{Manuel Guzmán Hennesy}

\author{
Editorial Universidad Bolivariana, Santiago, 2009, \\ 306 págs.
}

\section{Antonio Elizalde Hevia*}

Recibido: 24.02 .2010

Aceptado: 17.03.0210

$* * *$

Desde una plataforma mental poco convencional, el enfoque del caos y la complejidad, el autor de este libro aventura una novedosa hipótesis interpretativa del fenómeno climático global. Plantea que la civilización del consumismo logró romper la dinámica natural de los ciclos orden caos, y abrió camino, durante la segunda mitad del siglo XX, a un segundo ciclo caos que podría llevarnos a la catástrofe que han advertido los científicos y estudiosos del tema.

Manuel Guzmán Hennesy se plantea aportar al necesario cambio de mirada que la humanidad debe realizar para encontrar una solución a la creciente y profunda sino catastrófica crisis a que nos enfrentamos. Él nos señala que «Con base en los informes del IPCC, y en la opinión de científicos como James Lovelock y James Hansen, entendí que el problema del cambio climático global tenía un origen sistémico, anclado en la cultura del consumismo y en la ideología del progreso, asuntos que había ayudado a construir la ciencia moderna, con excesivo como arrogante denuedo.»

Su propuesta es aprender a «ver entero», y de ese modo facilitar los procesos de autoorganización relacionados con una modificación estructural de nuestro actual sistema de creencias, para que así podamos encontrar, entre todos, una salida a la crisis, aunque no en el corto plazo, sí en el mediano. Su apuesta se basa en una esperanza «de que nos alcance el tiempo para que hallemos esta salida antes de que el punto de no retorno del cambio climático global, haga irreversibles sus efectos de deterioro sobre los ecosistemas, naturales y construidos, que hoy se encuentran en situación de grave riesgo». Es esa esperanza la que lo ha llevado a escribir este libro.

\footnotetext{
*Universidad Bolivariana, Santiago, Chile. Email: aelizalde@ubolivariana.cl
} 
Esta interesante aproximación que Manuel Guzmán nos aporta la ancla en su profunda formación en los enfoques de la complejidad y del caos, desde los cuales analiza la realidad a la cual hemos llegado como producto de nuestra, sino ceguera, al menos evidente miopía, con la cual nos hemos conducido como civilización en los últimos dos siglos.

Somos muchos quienes compartimos la convicción y esperanza que anima al autor de este libro, pues estamos absolutamente convencidos que la humanidad enfrenta una amenaza de una importancia como nunca antes en la historia de su devenir evolutivo.

El texto que tenemos entre nuestras manos agrega a los ya conocidos antecedentes respecto al aumento de la concentración de dióxido de carbono en la atmósfera, como causa única del calentamiento global, la consideración de otros factores antropogénicos, en especial el consumismo, factor cultural íntimamente ligado al esquema de creencias instalado en el imaginario colectivo de la humanidad por las ideas de progreso, de crecimiento, de desarrollo, de bienestar y de felicidad, propias de la civilización humana del siglo XX. Su autor analiza la problemática de esta crisis, desde el enfoque de la teoría del caos, incorporando algunos modelos de análisis complejos de la realidad, aportados desde diferentes aproximaciones disciplinarias tales como la economía, la sociología, las ciencias cognitivas, la filosofía de la ciencia y la física. Parte del supuesto que la paradoja ordencaos, nos puede proveer una oportunidad interpretativa, que haga posible revisar estructuralmente el modelo de desarrollo sostenible, que más temprano deberá ineludiblemente asumir la actual civilización.

Para ello sugiere modificar la forma hegemónica de ver la realidad instalada muy profundamente en nuestro imaginario colectivo y que nos hace verla como fragmentada y separada y en realidades disociadas - mediante los enfoques más recientes y audaces de la nueva ciencia y la nueva filosofía de la ciencia, que nos proveen de una aproximación o enfoque sistémico, esto es una nueva mirada sobre la realidad de la cual formamos parte. De allí su insistencia en la metáfora del "ver entero" y en aportarnos en su obra elementos que nos hagan posible avanzar en la construcción de una metodología de "ver entero".

Metodología esta que toma de los trabajos de John Briggs y F. D. Peat sobre el "dejarse ir", pero que ancla su sentido más profundo en el concepto de autoorganización. Noción que a su vez emparenta con la reflexión de Inmanuel Kant en su Crítica del Juicio, y que llega hasta la Escuela parisina de sistemas autoorganizados, que dirige Henri Atlan. Incorpora, asimismo, los modelos provistos por Hazel Henderson en su libro Guía para montar el tigre del cambio y por Taichi Sakaiya en su obra Historia del futuro: la sociedad del conocimiento sobre el "impulso empático".

Manuel Guzmán ha construido su argumento pensando en un público muy concreto que es para quienes escribe esta obra. Está conformado por aquellos a quienes él llama "la generación del cambio climático glo- 
bal”, que son sus alumnos de hoy, pero que serán quienes tendrán las responsabilidades de dirigir - mediante el ejercicio de sus profesiones - desde el mundo empresarial, político y técnico burocrático, la sociedad que habitará nuestro Planeta Tierra a mediados del siglo que recién iniciamos.

Aunque su pretensión parezca ambiciosa, ella está profundamente anclada en la casi olvidada virtud de la esperanza, puesto que busca influir en unos pocos de aquellos a quienes tuvo en mente al escribir este libro, con la apuesta implícita de que entre ellos puedan encontrarse, aquellos "pocos iluminados o pioneros, que alumbran a sus congéneres el camino a seguir. Desde hace mucho tiempo he tenido predilección por el azar, por la práctica cotidiana del enfoque del caos y la totalidad, ello me ha facilitado la fortuna de hallar, entre la inasible madeja de seres humanos que compone el plural Universo, a esos pocos "iluminados.”

La hipótesis presentada explícitamente en este libro es que la humanidad experimentará un nuevo renacimiento distinto del ocurrido en el siglo XIV y XV y que será realizado por la generación del cambio climático global (2020 - 2050). Sostiene que las expectativas puestas en los acuerdos de Kyoto se verán frustradas porque no se cumplirán las metas planteadas lo cual nos conducirá a topar el fondo de la crisis climática global a mediados del actual siglo. Esta crisis nos dará la posibilidad de nuevo renacimiento de la cultura humana, que se anclaría en un profundo proceso de cambio epistemológico en el sistema de creencias de la humanidad, y no, los simples cambios cosméticos a los cuales estamos acostumbrados y que vienen orquestados desde lo político, lo económico o lo tecnológico.

De allí la necesidad que la humanidad cambie de estrategia, y en lugar de confiar exclusivamente en el Protocolo de Kyoto, o en la ilusión de obtener frustrados acuerdos del tipo de los esperados y no logrados en Copenhagen, comience a diseñar un plan de supervivencia de tipo tribal, que sin excluir los necesarios aunque insuficientes acuerdos internacionales, ponga el énfasis en la adaptación global y sistemática de la cultura. Revisar el modelo de desarrollo sostenible, cambiar nuestro sistema de creencias y modificar la ideología del progreso son tres de los pilares que el autor propone como necesarios para recuperar la esperanza de las generaciones venideras.

Los ejes estructurantes de este cambio estructural de las creencias incluirán entre otros: la prevalencia de la intuición sobre la razón, que haría posible "un nuevo modelo de desarrollo económico y social, basado en la equidad, la sostenibilidad y el crecimiento moderado”, así como la necesaria integración de la ética con la estética, como soportes de un nuevo tipo de progreso y de un nuevo paradigma de felicidad.

A muchos lo escrito en este libro les podrá parecer iluso e incluso ingenuo, pero para muchos otros, posiblemente muchos más, les servirá tal como un faro, para iluminar el incierto, desafiante y promisorio futuro que les tocará enfrentar en los años que se avecinan. 